\title{
Multifocal Toric Intraocular Lens for Traumatic Cataract in a Child
}

\author{
Yanfeng Zeng ${ }^{a} \quad L^{2}$ cheng Fan ${ }^{b}$ Peirong $L^{c}$

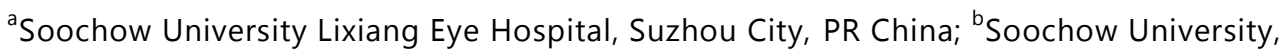 \\ Suzhou City, PR China; ${ }^{\circ}$ Department of Ophthalmology, the First Affiliated Hospital of \\ Soochow University, Suzhou City, PR China
}

\section{Keywords}

Multifocal toric intraocular lens · ReSTOR Toric intraocular lens · Astigmatism · Traumatic cataract $\cdot$ Children

\begin{abstract}
A child suffering from traumatic cataract and corneal astigmatism of $2.14 \mathrm{D}$ had a phacoemulsification operation and implantation of a ReSTOR Toric intraocular lens (IOL) to correct the astigmatism. The primary outcome measurements were the uncorrected distance visual acuity (UDVA), uncorrected near vision at $40 \mathrm{~cm}$, intraocular pressure, spherical equivalent refraction, residual astigmatism, corneal astigmatism, presence of unusual optical phenomena, and use of spectacles. At 7 months postoperatively, UDVA was maintained between $16 / 20$ and $24 / 20$, near vision was between $J 1$ and $J 3$, residual spherical refraction was 0 $0.37 \mathrm{D}$, and residual refractive cylinder was between 0 and $0.67 \mathrm{D}$. A multifocal toric IOL can provide the possibility of satisfactory vision for both distant and near conditions without the use of spectacles to meet children's needs when studying and doing sports. Additionally, binocular vision can be reconstructed. This intervention, therefore, seems to be a satisfactory alternative.




\section{Case Reports in Ophthalmology}

\section{Introduction}

Modern cataract surgery is entering the era of refractive surgery, allowing people not only to be able to see but also to be able to see clearly at all distances. It is well known that the presence of astigmatism in the eye in which the multifocal intraocular lens (IOL) is implanted can affect vision $[1,2]$. The prevalence of preoperative astigmatism in patients undergoing cataract surgery has been estimated to be between 15 and 29\% [3-5]. There are many techniques to correct corneal astigmatism, including corneal limbal relaxing incision [6-10]. Recent studies have shown that the implantation of an astigmatism-corrected IOL is more effective [11]. ReSTOR Toric has the advantages of the multifocal astigmatism correction of an artificial lens, and it can correct astigmatism. Children with cataracts who have lost vision not only need to see clearly at both near and far distances without the use of spectacles to meet the needs when studying and doing sports, but also to reconstruct the binocular visual function. In this case report, the effects and complications of ReSTOR Toric in the eye of a child with traumatic cataract and astigmatism were observed.

\section{Case History}

The boy presented in this case report was 9 years old. His left eye had been hit inadvertently by plastic pellets 2 years prior to surgery. The visual acuity decreased gradually. An ocular examination revealed right-eye visual acuity of 20/20 and left-eye visual acuity of 3/20; intraocular pressure was $15 \mathrm{~mm} \mathrm{Hg}$ (left eye), the cornea was transparent, the anterior chamber was normal in depth, the iris was clear, and the pupil diameter was $3 \mathrm{~mm}$ and sensitive to light reflection. The lens was opaque (upper temporal significant T-shaped porcelain white opacity) with posterior capsular opacity. The fundus could be seen vaguely after mydriasis. Corneal endothelial cell count was 2,332.8/ $\mathrm{mm}^{2}$ (left eye); B-scan ultrasonography detected no obvious abnormalities in the eyes. Axial length (AL) was $23.55 \mathrm{~mm}$, $\mathrm{K} 1 / \mathrm{K} 2$ was $41.82 \mathrm{D} / 43.95 \mathrm{D}$, and cylinder was $-2.13 \mathrm{D}$ at $174^{\circ}$ (left-eye corneal topography). The IOL degree was $21.0 \mathrm{D}$, and AL was also $23.55 \mathrm{~mm}$.

\section{Case Report}

The child's parents wanted the patient to have a chance to see near and far clearly without glasses to meet the needs when studying and doing sports. ReSTOR Toric combines the advantages of an artificial lens with the astigmatism correction of an IOL and the advantages of a multifocal IOL. The diffractive aspect of the IOL optical part is a step height of the diffraction pattern from the centre to the periphery of the optical part. The diffraction pattern is located at the front surface of the IOL. The optical surface is non-spherical, which can improve the contrast sensitivity and compensate for the physiological spherical aberration of the cornea. In cataract surgery, the benefits of using a non-spherical IOL have been widely described in the literature. In most patients, these IOLs can provide a higher visual quality $[12,13]$. The patient's eye records were as follows: K1: $41.82 \mathrm{D} \times 174^{\circ}$ (corneal curvature), K2: $43.95 \mathrm{D} \times 84^{\circ}$ (steep corneal curvature), $0.50 \mathrm{D}$ (SIA), $135^{\circ}$ (design incision position), and the IOL power was calculated as $21.0 \mathrm{D}$ (SND1T5). The astigmatism axial angle was $77^{\circ}$. The addition of SND1T5 to IOL in the plane is $+3.00 \mathrm{D}$, which corresponds to $+2.25 \mathrm{D}$ near vision and corrects $+2.0 \mathrm{D}$ astigmatism. Because the child had a history of trauma, a multifo- 


\section{Case Reports in Ophthalmology}

cal IOL would not have been implanted if the capsule bag had been torn. The child's parents agreed to the operation.

For 3 days before the operation, $0.3 \%$ ofloxacin was applied as eye drops. The ReSTOR Toric IOL axial position was labelled with a marking pen after topical anaesthesia, and then the pupil was dilated with Mydrin-P. The operation was performed under general anaesthesia. The corneal incision was made manually using a $2.2-\mathrm{mm}$ keratome and a $0.75-\mathrm{mm}$ sideport blade. The patient underwent continuous curvilinear capsulorhexis, hydrodissection, and phacoemulsification. Phacoemulsification suction was $350 \mathrm{~mm} \mathrm{Hg}$, flow was $35 \mathrm{ml} / \mathrm{min}$, and emulsifying time was $17.8 \mathrm{~s}$. After successful removal of the lens cortex, the posterior capsule and anterior capsules were polished. Then, the IOL was placed in the capsular bag. Lens astigmatism axial angle was adjusted to $77^{\circ}$. After successful removal of the viscoelastic agent, the anterior chamber was formatted. The eye was coated with tobramycin dexamethasone oculentum and covered with a sterile gauze mask. Postoperatively, the patient was prescribed topical tobramycin dexamethasone eye drops for 4 weeks.

Follow-up was performed at 1 day, 3 days, 1 week, 1 month, 2, 3 and 7 months after surgery. At each visit, the eye was scanned using a dioptre corneal analyser system (Nidek Co., Ltd.) for automatic optometry. A brief questionnaire on the use of glasses was carried out. Questions included 'Do you wear glasses?' and whether there were halo glare, astral glare, ghosting and diplopia, or discomfort phenomena. Each question had 4 options for the answer: never; in some cases; in most cases, and always. The patient reported no halo glare, astral glare, ghosting and diplopia, or discomfort phenomena. The far visual acuity remained between $16 / 20$ and 24/20, and the near visual acuity remained between J1 and J3 without the use of spectacles at any distance during 7 months of follow-up.

\section{Discussion}

In the face of paediatric cataract, many doctors only pay attention to achieving superb surgical techniques and good surgical results and overlook the fact that children who have lost binocular vision also need reconstruction of binocular visual function. To rebuild binocular visual function, the most important problem is how to choose the artificial crystal with the best optical effect, specifically the effect most consistent with human physiology [14]. In most cases, school-age children receive treatments restoring vision in the near distance because their demand for near vision is higher than that of adults. Due to the lack of multifocal capability, single-focus IOLs are far from meeting patients' needs for learning and life. Multifocal IOLs can make far and near objects appear on the retina, thereby meeting the different requirements of vision at the same time. This approach can solve the problem of the lack of adjustment of a single-focus IOL to achieve normal or close to normal vision. Multifocal IOLs have been reported as a good alternative to a monofocal IOL in cooperative children over 4 years of age with unilateral cataract [15]. However, most cataract patients also suffer from astigmatism. In a study of 4,540 patients, $87 \%$ patients had various degrees of astigmatism before cataract surgery, $64 \%$ of patients were between 0.2 and $1.25 \mathrm{D}, 22 \%$ of patients were above $1.5 \mathrm{D}$, and 5 or $6 \%$ of patients with astigmatism were even above $2 \mathrm{D}$. It is well known that the astigmatism of the eye of the diffractive multifocal IOL can impair vision. Therefore, astigmatism of $1 \mathrm{D}$ or higher should be corrected. Many studies have demonstrated the safety and effectiveness of various methods of astigmatism correction after implantation of a multifocal IOL, including laser-assisted in situ keratomileusis and limbal relaxing incision $[16,17]$. However, these methods are ineffective, unpredictable, or require two operations. 
Case Reports in
Ophthalmology

Case Rep Ophthalmol 2016;7:203-207

DOI: $10.1159 / 000449153$

C 2016 The Author(s). Published by S. Karger AG, Basel www.karger.com/cop

Zeng et al.: Multifocal Toric Intraocular Lens for Traumatic Cataract in a Child

The multifocal astigmatism-correcting type of IOL has the ability to correct astigmatism in a single operation. AcrySof astigmatism correction $[18,19]$ has been tested in randomized trials to confirm its safety, effectiveness, rotational stability, optical quality, and subjective patient satisfaction. A clinical study of the 3.00- and 4.00-D IOL confirmed their safety and effectiveness, optical quality, and patient satisfaction [20,21]. A diffractive multifocal toric IOL reduces astigmatism more than a monofocal IOL and provides more satisfactory near vision [22]. The astigmatism correction was safe and effective and can be expected to remain satisfactory [23], and it also decreased the rate of spectacle use [24]. Because the child's AL was $23.76 \mathrm{~mm}$, greater than $23 \mathrm{~mm}$, we used the SRK/T formula. Negative optical phenomena (halo, glare, astral, ghost, and diplopia) are inherent in a diffractive multifocal IOL design because the different annular zones of the step edges produce these phenomena. However, there were no glare, halo, or discomfort phenomena in our study.

\section{Conclusion}

Our results show that the implantation of an AcrySof IQ ReSTOR Toric IOL provided excellent far and near vision in a patient over 6 years of age, offering the pseudophakic patient the possibility of satisfactory vision for both distant and near conditions while reconstructing binocular visual function without the use of spectacles to meet children's needs when studying and doing sports. In this case, the IOL Master showed good repeatability in terms of the corneal topography, $\mathrm{AB}$ ultra, and the optometric tests that could be performed. The development of abnormal children with astigmatism in cataract patients with multifocal light IOLs can produce better visual acuity, better stereo vision, and no obvious visual symptoms and complications. This approach allows the pseudophakic eye to function with its fellow eye, which has active accommodation. It may be a good alternative for children over 6 years of age with unilateral cataract.

\section{Acknowledgements}

This work was supported in part by an unrestricted grant from Soochow University Lixiang Eye Hospital, China, and by the National Natural Science Foundation of China (project approval No. 61475108).

\section{Statement of Ethics}

The study conformed to the tenets of the Declaration of Helsinki.

\section{Disclosure Statement}

The authors have no potential financial conflicts of interest. 


\section{Case Reports in Ophthalmology}

\section{References}

1 Hayashi K, Manabe S-I, Yoshida M, Hayashi H: Effect of astigmatism on visual acuity in eyes with a diffractive multifocal intraocular lens. J Cataract Refract Surg 2010;36:1323-1329.

-2 Fernandez-Vega L, Alfonso JF, Montes-Mico R, Amhaz H: Visual acuity tolerance to residual refractive errors in patients with an apodized diffractive intraocular lens. J Cataract Refract Surg 2008;34:199204.

-3 Khan MI, Muhtaseb M: Prevalence of corneal astigmatism in patients having routine cataract surgery at a teaching hospital in the United Kingdom. J Cataract Refract Surg 2011;37:1751-1755.

-4 Hoffmann PC, Hütz WW: Analysis of biometry and prevalence data for corneal astigmatism in 23,239 eyes. J Cataract Refract Surg 2010;36:1479-1485.

5 Ferrer-Blasco T, Montés-Micó R, Peixoto-de-Matos SC, González-Méijome JM, Cervino A: Prevalence of corneal astigmatism before cataract surgery. J Cataract Refract Surg 2009;35:70-75.

-6 Ouchi M, Kinoshita S: AcrySof IQ toric IOL implantation combined with limbal relaxing incision during cataract surgery for eyes with astigmatism 2.50 D. J Refract Surg 2011;27:643-647.

-7 Qammar A, Mullaney P: Paired opposite clear corneal incisions to correct preexisting astigmatism in cataract patients. J Cataract Refract Surg 2005;31:1167-1170.

-8 Gunvant P, Ablamowicz A, Gollamudi S: Predicting the necessity of LASIK enhancement after cataract surgery in patients with multifocal IOL implantation. Clin Ophthalmol 2011;5:1281-1285.

- Kim P, Sutton GL, Rootman DS: Applications of the femtosecond laser in corneal refractive surgery. Curr Opin Ophthalmol 2011;22:238-244.

10 Mendicute J, Irigoyen C, Ruiz M, Illarramendi I, Ferrer-Blasco T, Montes-Mico R: Toric intraocular lens versus opposite clear corneal incisions to correct astigmatism in eyes having cataract surgery. J Cataract Refract Surg 2009;35:451-458.

11 Mingo-Botín D, Muñoz-Negrete FJ, Won Kim HR, Morcillo-Laiz R, Rebolleda G, Oblanca N: Comparison of toric intraocular lenses and peripheral corneal relaxing incisions to treat astigmatism during cataract surgery. J Cataract Refract Surg 2010;36:1700-1708.

12 Kohnen T, Klaproth OK, Bühren J: Effect of intraocular lens asphericity on quality of vision after cataract removal; an intraindividual comparison. Ophthalmology 2009;116:1697-1706.

13 Cui H, Hu R, Zhang Y, Lou D: Comparison of pseudophakic visual quality in spherical and aspherical intraocular lenses. Can J Ophthalmol 2009;44:274-278.

14 Liu LM: Preliminary clinical effect observation to pediatric cataract implanted with multifocal intraocular lens [dissertation]. Jinan, University of Jinan, 2013, pp 26-27.

-15 Cristóbal JA, Remón L, Del Buey MÁ, Montés-Micó R: Multifocal intraocular lenses for unilateral cataract in children. J Cataract Refract Surg 2010;36:2035-2040.

16 Muftuoglu O, Prasher P, Chu C, Mootha VV, Verity SM, Cavanagh HD, Bowman RW, McCulley JP: Laser in situ keratomileusis for residual refractive errors after apodized diffractive multifocal intraocular lens implantation. J Cataract Refract Surg 2009;35:1063-1071.

17 Muftuoglu O, Dao L, Cavanagh HD, McCulley JP, Bowman RW: Limbal relaxing incisions at the time of apodized diffractive multifocal intraocular lens implantation to reduce astigmatism with or without subsequent laser in situ keratomileusis. J Cataract Refract Surg 2010;36:456-464.

-18 Mendicute J, Irigoyen C, Aramberri J, Ondarra A, Montes-Mico R: Foldable toric intraocular lens for astigmatism correction in cataract patients. J Cataract Refract Surg 2008;34:601-607.

19 Shah GD, Praveen MR, Vasavada AR, Vasavada VA, Rampal G, Shastry LR: Rotational stability of a toric intraocular lens: influence of axial length and alignment in the capsular bag. J Cataract Refract Surg 2012;38:54-59.

20 Kohnen T, Nuijts R, Levy P, Haefliger E, Alfonso JF: Visual function after bilateral implantation of apodized diffractive aspheric multifocal intraocular lenses with a C3.0 D addition. J Cataract Refract Surg 2009;35:2062-2069.

-21 Lane SS, Javitt JC, Nethery DA, Waycaster C: Improvements in patient-reported outcomes and visual acuity after bilateral implantation of multifocal intraocular lenses with C3.0 diopter addition: multicenter clinical trial. J Cataract Refract Surg 2010;36:1887-1896.

22 Hayashi K, Masumoto M, Takimoto M: Comparison of visual and refractive outcomes after bilateral implantation of toric intraocular lenses with or without a multifocal component. J Cataract Refract Surg 2015;41:73-83.

23 Crema AS, Walsh A, Ventura BV, Santhiago MR: Visual outcomes of eyes implanted with a toric multifocal intraocular lens. J Refract Surg 2014;30:486-491.

-24 Knorz MC, Rincón JL, Suarez E, Alfonso JF, Fernández-Vega L, Titke C, Kohnen T, Tucker S: Subjective outcomes after bilateral implantation of an apodized diffractive +3.0 D multifocal toric IOL in a prospective clinical study. J Refract Surg 2013;29:762-767. 